\title{
Existence and Convergence Theorems of Best Proximity Points
}

\author{
Moosa Gabeleh ${ }^{1}$ and Naseer Shahzad ${ }^{2}$ \\ ${ }^{1}$ Department of Mathematics, Ayatollah Boroujerdi University, Boroujerd, Iran \\ ${ }^{2}$ Department of Mathematics, King Abdulaziz University, P.O. Box 80203, Jeddah 21589, Saudi Arabia \\ Correspondence should be addressed to Naseer Shahzad; nshahzad@kau.edu.sa \\ Received 22 February 2013; Accepted 16 April 2013 \\ Academic Editor: Gue Myung Lee
}

Copyright (c) 2013 M. Gabeleh and N. Shahzad. This is an open access article distributed under the Creative Commons Attribution License, which permits unrestricted use, distribution, and reproduction in any medium, provided the original work is properly cited.

The aim of this paper is to prove some best proximity point theorems for new classes of cyclic mappings, called pointwise cyclic orbital contractions and asymptotic pointwise cyclic orbital contractions. We also prove a convergence theorem of best proximity point for relatively nonexpansive mappings in uniformly convex Banach spaces.

\section{Introduction and Preliminaries}

Let $(X, d)$ be a metric space, and let $A, B$ be subsets of $X$. A mapping $T: A \cup B \rightarrow A \cup B$ is said to be cyclic provided that $T(A) \subseteq B$ and $T(B) \subseteq A$. In 2003, Kirk et al. [1] proved the following generalization of Banach contraction principle.

Theorem 1 (see [1]). Let $A$ and $B$ be nonempty closed subsets of a complete metric space $(X, d)$. Suppose that $T$ is a cyclic mapping such that

$$
d(T x, T y) \leq \alpha d(x, y)
$$

for some $\alpha \in(0,1)$ and for all $x \in A, y \in B$. Then $T$ has a unique fixed point in $A \cap B$.

In [2] Eldred and Veeramani introduced the class of cyclic contractions as follows.

Definition 2 (see [2]). Let $A$ and $B$ be nonempty subsets of a metric space $X$. A mapping $T: A \cup B \rightarrow A \cup B$ is said to be a cyclic contraction if $T$ is cyclic and

$$
d(T x, T y) \leq \alpha d(x, y)+(1-\alpha) \operatorname{dist}(A, B),
$$

for some $\alpha \in(0,1)$ and for all $x \in A, y \in B$.
Let $T$ be a cyclic mapping. A point $x \in A \cup B$ is said to be a best proximity point for $T$ provided that $d(x, T x)=\operatorname{dist}(A, B)$, where

$$
\operatorname{dist}(A, B):=\inf \{d(x, y): x \in A, y \in B\} .
$$

Note that if $\operatorname{dist}(A, B)=0$, then the best proximity point is nothing but a fixed point of $T$.

The next theorem ensures existence, uniqueness, and convergence of best proximity point for cyclic contractions in uniformly convex Banach spaces.

Theorem 3 (see [2]). Let $A$ and $B$ be nonempty closed convex subsets of a uniformly convex Banach space $X$ and let $T: A \cup$ $B \rightarrow A \cup B$ be a cyclic contraction map. For $x_{0} \in A$, define $x_{n+1}:=T x_{n}$ for each $n \geq 0$. Then there exists a unique $x \in A$ such that $x_{2 n} \rightarrow x$ and $\|x-T x\|=\operatorname{dist}(A, B)$.

Recently, Suzuki et al. in [3] introduced the notion of property UC which is a kind of geometric property for subsets of a metric space $X$.

Definition 4 (see [3]). Let $A$ and $B$ be nonempty subsets of a metric space $(X, d)$. Then $(A, B)$ is said to satisfy property UC if the following holds. 
If $\left\{x_{n}\right\}$ and $\left\{z_{n}\right\}$ are sequences in $A$ and $\left\{y_{n}\right\}$ is a sequence in $B$ such that $\lim _{n} d\left(x_{n}, y_{n}\right)=\operatorname{dist}(A, B)$ and $\lim _{n} d\left(z_{n}, y_{n}\right)=$ $\operatorname{dist}(A, B)$, then we have $\lim _{n} d\left(x_{n}, z_{n}\right)=0$.

We mention that if $A$ and $B$ are nonempty subsets of a uniformly convex Banach space $X$ such that $A$ is convex, then $(A, B)$ satisfies the property UC. Other examples of pairs having the property UC can be found in [3]. Here, we state the following two lemmas of [3].

Lemma 5 (see [3]). Let $A$ and $B$ be nonempty subsets of $a$ metric space $(X, d)$. Assume that $(A, B)$ satisfies the property $U C$. Let $\left\{x_{n}\right\}$ and $\left\{y_{n}\right\}$ be sequences in $A$ and $B$, respectively, such that either of the following holds:

$$
\begin{aligned}
\lim _{m \rightarrow \infty} \sup _{n \geq m} d\left(x_{m}, y_{n}\right)=d(A, B) \\
\text { or } \quad \lim _{n \rightarrow \infty} \sup _{m \geq n} d\left(x_{m}, y_{n}\right)=d(A, B) .
\end{aligned}
$$

Then $\left\{x_{n}\right\}$ is a Cauchy sequence.

Lemma 6 (see [3]). Let $(X, d)$ be a metric space and let $A$ and $B$ be nonempty subsets of $X$ such that $(A, B)$ satisfies the property UC. Let $T: A \cup B \rightarrow A \cup B$ be a cyclic map such that

$$
\begin{gathered}
d\left(T^{2} x, T x\right) \leq d(x, T x) \quad \forall x \in A, \\
d\left(T^{2} x, T x\right)<d(x, T x) \quad \forall x \in A \\
\text { with } \operatorname{dist}(A, B)<d(x, T x) .
\end{gathered}
$$

For a point $z \in A$, the following are equivalent:

(i) $z$ is a best proximity point of $T$;

(ii) $z$ is a fixed point of $T^{2}$.

Throughout this paper, $(A, B)$ stands for a nonempty pair in a metric space $(X, d)$. When we say that a pair $(A, B)$ satisfies a specific property, we mean that both $A$ and $B$ satisfy the mentioned property. Also, we define $(A, B) \subseteq(C, D) \Leftrightarrow$ $A \subseteq C$ and $B \subseteq D$. Moreover, we use the following notations:

$$
\begin{gathered}
\delta_{x}(A)=\sup \{d(x, y): y \in A\} \quad \forall x \in X, \\
\delta(A, B)=\sup \{d(x, y): x \in A, y \in B\}, \\
\operatorname{diam}(A)=\delta(A, A) .
\end{gathered}
$$

For a cyclic mapping $T: A \cup B \rightarrow A \cup B$ and $x \in A \cup B$, we define the orbit setting at $x$ by

$$
\mathcal{O}_{T^{2}} x:=\left\{x, T^{2} x, T^{4} x, \ldots, T^{2 n} x, \ldots\right\},
$$

where $T^{2 n} x=T\left(T^{2 n-1} x\right)$ for $n \geq 1$ and $T^{0} x=x$. We set

$$
\mathcal{O}_{T^{2}}(x, y):=\mathcal{O}_{T^{2}}(x) \cup \mathcal{O}_{T^{2}}(y),
$$

for all $x, y \in A \cup B$. Note that if $(x, y) \in A \times B$, then $\mathcal{O}_{T^{2}} x \subseteq A$ and $\mathcal{O}_{T^{2}} y \subseteq B$. Also, the set of all best proximity points of the mapping $T$ in $A$ will be denoted by B.P.P $(T) \cap A$.
We mention that a mapping $T: A \cup B \rightarrow A \cup B$ is said to be relatively nonexpansive provided that $T$ is cyclic and satisfies the condition $\|T x-T y\| \leq\|x-y\|$ for each $(x, y) \in$ $A \times B$. Note that a relatively nonexpansive mapping need not be a continuous mapping. Also every nonexpansive self-map can be considered as a relatively nonexpansive mapping.

In 2005 Eldred et al. in [4] introduced a geometric concept called proximal normal structure. Using this notion they proved that if $(A, B)$ is a nonempty weakly compact convex pair in a Banach space $X$ and $T: A \cup B \rightarrow A \cup B$ is a relatively nonexpansive mapping, then there exists $(x, y) \in$ $A \times B$ such that $\|x-T x\|=\|T y-y\|=\operatorname{dist}(A, B)$. For more details on this subject, we refer the reader to [5-10].

\section{Pointwise Cyclic Orbital Contractions}

In [11], the notion of pointwise cyclic contractions was introduced as follows.

Definition 7 (see [11]). Let $(A, B)$ be a pair of subsets of a metric space $(X, d)$. Let $T: A \cup B \rightarrow A \cup B$ be a cyclic mapping. $T$ is said to be a pointwise cyclic contraction if for each $(x, y) \in A \times B$ there exist $0 \leq \alpha(x)<1,0 \leq \alpha(y)<1$ such that

$$
\begin{array}{r}
d(T x, T y) \leq \alpha(x) d(x, y)+(1-\alpha(x)) \operatorname{dist}(A, B) \\
\forall y \in B, \\
d(T x, T y) \leq \alpha(y) d(x, y)+(1-\alpha(y)) \operatorname{dist}(A, B) \\
\forall x \in A .
\end{array}
$$

The following result was proved in [11].

Theorem 8 (see [11]). Let $(A, B)$ be a nonempty weakly compact convex pair in a Banach space $X$ and suppose that $T$ is a pointwise cyclic contraction mapping. Then there exists $(x, y) \in A \times B$ such that $\|x-T x\|=\|y-T y\|=\operatorname{dist}(A, B)$.

In this section, we introduce a new class of cyclic mappings, called pointwise cyclic orbital contractions, which contains the pointwise cyclic contractions as a subclass. For such mappings, we study the existence of best proximity points in Banach spaces.

Definition 9. Let $(A, B)$ be a pair of subsets of a metric space $(X, d)$. A cyclic mapping $T: A \cup B \rightarrow A \cup B$ is said to be a pointwise cyclic orbital contraction if there exists $\alpha: A \cup$ $B \rightarrow[0,1)$ such that for each $(x, y) \in A \times B$

$$
\begin{array}{r}
d(T x, T y) \leq \alpha(x) \delta_{x}\left(\mathcal{O}_{T^{2}} y\right)+(1-\alpha(x)) \operatorname{dist}(A, B) \\
\forall y \in B, \\
d(T x, T y) \leq \alpha(y) \delta_{y}\left(\mathcal{O}_{T^{2}} x\right)+(1-\alpha(y)) \operatorname{dist}(A, B) \\
\forall x \in A .
\end{array}
$$

It is clear that the class of pointwise cyclic orbital contractions contains the class of pointwise cyclic contractions as a subclass. The following example shows that the converse need 
not be true. Moreover, it is interesting to note that a pointwise cyclic orbital contraction may not be relatively nonexpansive.

Example 10. Let $X:=\mathbb{R}$ with the usual metric. For $A=B=$ $[0,1 / 2]$, define $T: A \cup B \rightarrow A \cup B$ by

$$
T x= \begin{cases}\frac{1}{8} x & \text { if } 0 \leq x \leq \frac{1}{4}, \\ 0 & \text { if } \frac{1}{4}<x \leq \frac{1}{2} .\end{cases}
$$

Then $T$ is pointwise cyclic orbital contraction with $\alpha(x)=$ $7 / 8$ for all $x \in A$.

Proof. If either $0 \leq x, y \leq 1 / 4$ or $1 / 4<x, y \leq 1 / 2$, then it is easy to see that relations (10) and (11) hold. Suppose that $0 \leq x \leq 1 / 4$ and $1 / 4<y \leq 1 / 2$. Thus,

$$
\begin{gathered}
d(T x, T y)=\frac{1}{8} x, \\
\delta_{x}\left(\mathcal{O}_{T^{2}} y\right)=\sup _{n \geq 0}\left|x-T^{2 n} y\right|=\max \{x, y-x\} .
\end{gathered}
$$

Hence,

$$
d(T x, T y)=\frac{1}{8} x \leq \frac{7}{8} \max \{x, y-x\}=\alpha(x) \delta_{x}\left(\mathcal{O}_{T^{2}} y\right),
$$

that is, (10) holds. Also, by the fact that $\delta_{y}\left(\mathcal{O}_{T^{2}} x\right)=\sup _{n \geq 0} \mid y-$ $T^{2 n} x \mid=y$ then

$$
d(T x, T y)=\frac{1}{8} x \leq \frac{7}{8} y=\alpha(y) \delta_{x}\left(\mathcal{O}_{T^{2}} x\right),
$$

which implies that (10) and (11) hold. Thus, $T$ is a pointwise cyclic orbital contraction. Now, we show that $T$ is not pointwise cyclic contraction. Indeed, if there exists a function $\alpha: A \cup B \rightarrow[0,1)$ such that $d(T x, T y) \leq \alpha(x) d(x, y)$ for all $(x, y) \in A \times B$, then for $x=1 / 4$ and $y=26 / 100$ we must have

$$
\frac{1}{8} \times \frac{25}{100}=d(T x, T y) \leq \alpha(x) d(x, y)=\alpha\left(\frac{25}{100}\right) \times \frac{1}{100},
$$

and hence $25 / 8 \leq \alpha(1 / 4)$, which is a contradiction. Therefore, $T$ is not pointwise cyclic contraction. Moreover, we note that since $T$ is not continuous, $T$ is not relatively nonexpansive.

Let us state our main result of this section.

Theorem 11. Let $(A, B)$ be a nonempty weakly compact convex pair in a Banach space X. If $T: A \cup B \rightarrow A \cup B$ is a pointwise cyclic orbital contraction, then the set of best proximity points of $T$ is nonempty.

Proof. Let $\Sigma$ denote the collection of all nonempty weakly compact convex pairs $(E, F)$ which are subsets of $(A, B)$ and such that $T$ is cyclic on $E \cup F$. Then $\Sigma$ is nonempty, since $(A, B) \in \Sigma$. $\Sigma$ is partially ordered by reverse inclusion; that is, $(A, B) \leq(C, D) \Leftrightarrow(C, D) \subseteq(A, B)$. It is easy to check that every increasing chain in $\Sigma$ is bounded above. Hence by Zorn's lemma we can get a minimal element say $\left(K_{1}, K_{2}\right) \in \Sigma$. We have

$$
\left(\overline{c o}\left(T\left(K_{2}\right)\right), \overline{c o}\left(T\left(K_{1}\right)\right)\right) \subseteq\left(K_{1}, K_{2}\right) .
$$

Moreover

$$
T\left(\overline{c o}\left(T\left(K_{2}\right)\right)\right) \subseteq T\left(K_{1}\right) \subseteq \overline{c o}\left(T\left(K_{1}\right)\right),
$$

and also

$$
T\left(\overline{c o}\left(T\left(K_{1}\right)\right)\right) \subseteq \overline{c o}\left(T\left(K_{2}\right)\right) .
$$

Now, by the minimality of $\left(K_{1}, K_{2}\right)$, we have $\overline{c o}\left(T\left(K_{2}\right)\right)=$ $K_{1}, \overline{c o}\left(T\left(K_{1}\right)\right)=K_{2}$. Suppose that $a \in K_{1}$. Then for each $y \in K_{2}$ we have

$$
\begin{aligned}
\|T a-T y\| & \leq \alpha(a) \delta_{a}\left(\mathcal{O}_{T^{2}} y\right)+(1-\alpha(a)) \operatorname{dist}(A, B) \\
& \leq \alpha(a) \delta_{a}\left(K_{2}\right)+(1-\alpha(a)) \operatorname{dist}(A, B),
\end{aligned}
$$

which implies that $T\left(K_{2}\right) \subseteq \mathscr{B}\left(T a ; \alpha(a) \delta_{a}\left(K_{2}\right)+(1-\alpha(a))\right.$ $\operatorname{dist}(A, B))$. Hence,

$$
\begin{aligned}
K_{1}= & \overline{c o}\left(T\left(K_{2}\right)\right) \\
& \subseteq \mathscr{B}\left(T a ; \alpha(a) \delta_{a}\left(K_{2}\right)+(1-\alpha(a)) \operatorname{dist}(A, B)\right) .
\end{aligned}
$$

Thus, for each $x \in K_{1}$ we must have

$$
\|x-T a\| \leq \alpha(a) \delta_{a}\left(K_{2}\right)+(1-\alpha(a)) \operatorname{dist}(A, B),
$$

which ensures that

$$
\delta_{T a}\left(K_{1}\right) \leq \alpha(a) \delta_{a}\left(K_{2}\right)+(1-\alpha(a)) \operatorname{dist}(A, B) .
$$

Similarly, we can see that if $b \in K_{2}$, then

$$
\delta_{T b}\left(K_{2}\right) \leq \alpha(b) \delta_{b}\left(K_{1}\right)+(1-\alpha(b)) \operatorname{dist}(A, B) .
$$

Assume that $(p, q)$ is a fixed element in $K_{1} \times K_{2}$. Let $\delta_{p}\left(K_{2}\right) \leq \delta_{q}\left(K_{1}\right)$. Set $r:=\delta_{p}\left(K_{2}\right)$ and

$$
\begin{aligned}
& E:=\left\{y \in K_{2}: \delta_{y}\left(K_{1}\right) \leq r\right\}, \\
& F:=\left\{x \in K_{1}: \delta_{x}\left(K_{2}\right) \leq r\right\} .
\end{aligned}
$$

Obviously, $p \in F$. Also, from (23) $T p \in E$ and then $(E, F)$ is a nonempty pair. Besides, it is easy to see that

$$
\begin{aligned}
E & :=\bigcap_{a \in K_{1}} \mathscr{B}(a ; r) \cap K_{2}, \\
F & :=\bigcap_{b \in K_{2}} \mathscr{B}(b ; r) \cap K_{1} .
\end{aligned}
$$

Now, let $y \in E$. Then $y \in K_{2}$ and by (24), $\delta_{T y}\left(K_{2}\right) \leq$ $\delta_{y}\left(K_{1}\right) \leq r$ which implies that $T y \in F$. Hence, $T(E) \subseteq F$. Similarly, by relation (23) we conclude that $T(F) \subseteq E$. That is, 
$T$ is cyclic on $E \cup F$. By the minimality of $\left(K_{1}, K_{2}\right)$ we must have $F=K_{1}$ and $E=K_{2}$. Therefore,

$$
\delta_{x}\left(K_{2}\right) \leq r, \quad \delta_{y}\left(K_{1}\right) \leq r,
$$

for each $(x, y) \in A \times B$. Then for all $(x, y) \in A \times B$ we have

$$
\delta_{x}\left(K_{2}\right) \leq \delta_{q}\left(K_{1}\right), \quad \delta_{y}\left(K_{1}\right) \leq \delta_{p}\left(K_{2}\right) .
$$

Particularly, $\delta_{p}\left(K_{2}\right) \leq \delta_{q}\left(K_{1}\right) \leq \delta_{p}\left(K_{2}\right)$. Thus,

$$
\delta_{p}\left(K_{2}\right)=\delta_{q}\left(K_{1}\right) .
$$

Similar argument implies that if $\delta_{q}\left(K_{1}\right) \leq \delta_{p}\left(K_{2}\right)$, then relation (29) is to be achieved. Therefore, (29) holds for all $(p, q) \in K_{1} \times K_{2}$. To complete the proof of the theorem, we consider the following cases.

Case 1. If $\delta_{p}\left(K_{2}\right)=\operatorname{dist}(A, B)$, then we have

$$
\|p-T p\| \leq \delta_{p}\left(K_{2}\right)=\operatorname{dist}(A, B),
$$

that is, $p$ is a best proximity point of $T$.

Case 2. If $\delta_{p}\left(K_{2}\right)>\operatorname{dist}(A, B)$, it now follows from (23) and (29) that

$$
\begin{aligned}
\delta_{p}\left(K_{2}\right) & =\delta_{T p}\left(K_{1}\right) \\
& \leq \alpha(p) \delta_{p}\left(K_{2}\right)+(1-\alpha(p)) \operatorname{dist}(A, B) \\
& <\delta_{p}\left(K_{2}\right),
\end{aligned}
$$

which is a contradiction. Hence, each point of $K_{1}$ is a best proximity point of $T$ and so $K_{1} \subseteq$ B.P.P $(T) \cap A$. Similarly, we can see that $K_{2} \subseteq \quad$ B.P.P $(T) \cap B$. Thus, for each $(x, y) \in$ $K_{1} \times K_{2}$ we must have

$$
\|x-T x\|=\|T y-y\|=\operatorname{dist}(A, B) .
$$

\section{Asymptotic Pointwise Cyclic Orbital Contractions}

Definition 12. Let $(A, B)$ be a pair of subsets of a metric space $(X, d)$. A cyclic mapping $T: A \cup B \rightarrow A \cup B$ is said to be an asymptotic pointwise cyclic orbital contraction if for each $(x, y) \in A \times B$,

$$
\begin{aligned}
d\left(T^{2 n} x, T^{2 n} y\right) \leq & \alpha_{n}(x) \operatorname{diam} \mathcal{O}_{T^{2}}(x, y) \\
& +\left(1-\alpha_{n}(x)\right) \operatorname{dist}(A, B) \quad \forall y \in B, \\
d\left(T^{2 n} x, T^{2 n} y\right) \leq & \alpha_{n}(y) \operatorname{diam} \mathcal{O}_{T^{2}}(x, y) \\
& +\left(1-\alpha_{n}(y)\right) \operatorname{dist}(A, B) \quad \forall x \in A,
\end{aligned}
$$

where for each $n \in \mathbb{N}, \alpha_{n}: A \cup B \rightarrow \mathbb{R}^{+}$and limsup $\sup _{n \rightarrow \infty} \alpha_{n}(x) \leq \eta$ for some $0<\eta<1$ and for all $x \in$ $A \cup B$.
The following theorem establishes existence and convergence of a best proximity point for asymptotic pointwise cyclic orbital contractions in metric spaces with the property UC.

Theorem 13. Let $(A, B)$ be a nonempty closed pair in a complete metric space $(X, d)$ such that $(A, B)$ satisfies the property $U C$. Assume that $T: A \cup B \rightarrow A \cup B$ is an asymptotic pointwise cyclic orbital contraction such that $T$ is continuous on A. If there exists $x \in A$ such that the orbit of $T$ at $x$ is bounded, then $T$ has a best proximity point in $A$. Moreover, if $x_{0} \in A$ and $x_{n+1}=T x_{n}$, then $\left\{x_{2 n}\right\}$ converges to the best proximity point of $T$.

Proof. Let $x \in A$. We note that the sequence $\left\{\operatorname{diam}\left[\mathcal{O}_{T^{2}}\left(T^{2 n} x, T^{2 n+1} x\right)\right]\right\}$ is decreasing and bounded below by $\operatorname{dist}(A, B)$. Let $\operatorname{diam}\left[\mathcal{O}_{T^{2}}\left(T^{2 n} x, T^{2 n+1} x\right)\right] \rightarrow r_{x} \geq$ $\operatorname{dist}(A, B)$. We claim that $r_{x}=\operatorname{dist}(A, B)$. For all $k_{1}, k_{2} \in \mathbb{N}$ with $k_{1} \leq k_{2}$ we have

$$
\begin{aligned}
d\left(T^{2\left(n+k_{1}\right)} x, T^{2\left(n+k_{2}\right)}(T x)\right) \\
\leq \alpha_{n+k_{1}}(x) \operatorname{diam}\left[\mathcal{O}_{T^{2}}(x, T x)\right] \\
\quad+\left(1-\alpha_{n+k_{1}}(x)\right) \operatorname{dist}(A, B) .
\end{aligned}
$$

Taking the supremum with respect to $k_{1}$ and $k_{2}$ and then letting $n \rightarrow \infty$ we obtain

$$
r_{x} \leq \eta \operatorname{diam}\left[\mathcal{O}_{T^{2}}(x, T x)\right]+(1-\eta) \operatorname{dist}(A, B) .
$$

Besides, for each $m \in \mathbb{N}$ we have

$$
\begin{aligned}
r_{x} & =\lim _{n \rightarrow \infty} \operatorname{diam}\left[\mathcal{O}_{T^{2}}\left(T^{2 n}\left(T^{2 m} x\right), T^{2 n}\left(T^{2 m}(T x)\right)\right)\right] \\
& \leq \eta \operatorname{diam} \mathcal{O}_{T^{2}}\left(T^{2 m} x, T^{2 m}(T x)\right)+(1-\eta) \operatorname{dist}(A, B) .
\end{aligned}
$$

Now, if $m \rightarrow \infty$ we obtain

$$
r_{x} \leq \eta r_{x}+(1-\eta) \operatorname{dist}(A, B),
$$

and hence $r_{x}=\operatorname{dist}(A, B)$. We now conclude that

$$
\lim _{n \rightarrow \infty} \sup _{m \geq n} d\left(T^{2 n} x, T^{2 m+1} x\right)=\operatorname{dist}(A, B) .
$$

Since $(A, B)$ has the property UC, by Lemma $5\left\{T^{2 n} x\right\}$ is a Cauchy sequence. Suppose that $x_{2 n} \rightarrow p$. Continuity of $T$ on $A$ implies that $x_{2 n+1} \rightarrow T p$. Thus, $d(p, T p)=\operatorname{dist}(A, B)$. That is, $p$ is a best proximity point of the mapping $T$ in $A$.

The next corollary is a direct result of Theorem 13 .

Corollary 14 (compare to Theorem 3). Let $(A, B)$ be a nonempty closed pair in a uniformly convex Banach space $X$ such that $A$ is convex. Assume that $T: A \cup B \rightarrow A \cup B$ is an asymptotic pointwise cyclic orbital contraction such that $T$ is continuous on $A$. If there exists $x \in A$ such that the orbit of $T$ at $x$ is bounded, then $T$ has a best proximity point in $A$. Moreover, if $x_{0} \in A$ and $x_{n+1}=T x_{n}$, then $\left\{x_{2 n}\right\}$ converges to the best proximity point of $T$. 


\section{A Convergence Theorem}

In this section, we give a convergence theorem of best proximity point for cyclic mappings which is derived from Ishikawa's convergence theorem ([12]). We begin with the following proposition which is an inequality characterization of uniformly convex Banach spaces.

Proposition 15 (see [13]). Let $X$ be a uniformly convex Banach space. Then for each $r>0$, there exists a strictly increasing, continuous and convex function $\varphi:[0,1) \rightarrow[0,1)$ such that $\varphi(0)=0$ and

$$
\|\lambda x+(1-\lambda) y\|^{2} \leq \lambda\|x\|^{2}+(1-\lambda)\|y\|^{2}-\lambda(1-\lambda) \varphi(\|x-y\|),
$$

for all $\lambda \in[0,1]$ and all $x, y \in X$ such that $\|x\| \leq r$ and $\|y\| \leq r$.

Definition 16. Let $(A, B)$ be a nonempty pair of subsets of a normed linear space $X$. Suppose that $T: A \cup B \rightarrow A \cup B$ is a cyclic mapping on $A \cup B$. We say that $T$ is hemicompactness on $A$ provided that each sequence $\left\{x_{n}\right\}$ in $A$ with $\left\|x_{n}-T^{2} x_{n}\right\| \rightarrow$ 0 has a convergent subsequence.

It is clear that if $A$ is compact set, then each cyclic mapping defined on $A \cup B$ is hemicompactness, where $B$ is a nonempty subset of $X$.

Theorem 17. Let $(A, B)$ be a nonempty, bounded, closed, and convex pair in a uniformly convex Banach space $X$. Assume that $T: A \cup B \rightarrow A \cup B$ is a cyclic relatively nonexpansive mapping such that $T$ is hemicompactness on $A$ and $T^{2}$ is continuous and satisfies the condition

$$
\left\|T^{2} x-T x\right\|<\|T x-x\|,
$$

for all $x \in A \cup B$ with $\|x-T x\|>\operatorname{dist}(A, B)$. Define a sequence $\left\{x_{n}\right\}$ in $A$ by $x_{1} \in A$ and

$$
x_{n+1}=\alpha x_{n}+(1-\alpha) T^{2} x_{n},
$$

for $n \in \mathbb{N}$, where $\alpha$ is a real number belonging to $(0,1)$. Then $\left\{x_{n}\right\}$ converges strongly to a best proximity point of $T$ in $A$.

Proof. Since $(A, B)$ is a bounded, closed, and convex pair in a uniformly convex Banach space $X$, the relatively nonexpansive mapping $T$ has a best proximity point in $B([4])$. Also, we note that both of the $(A, B)$ and $(B, A)$ have the property UC. So, by Lemma 6 a point $p \in B$ is a best proximity point of the mapping $T$ if and only if $p$ is a fixed point of the mapping $\left.T^{2}\right|_{B}$. We now have

$$
\begin{aligned}
\| x_{n+1} & -p \| \\
& =\left\|\alpha x_{n}+(1-\alpha) T^{2} x_{n}-T^{2} p\right\| \\
& =\left\|\alpha x_{n}+(1-\alpha) T^{2} x_{n}-\alpha T^{2} p-(1-\alpha) T^{2} p\right\| \\
& \leq \alpha\left\|x_{n}-p\right\|+(1-\alpha)\left\|T^{2} x_{n}-T^{2} p\right\| \\
& \leq \alpha\left\|x_{n}-p\right\|+(1-\alpha)\left\|x_{n}-p\right\|=\left\|x_{n}-p\right\| .
\end{aligned}
$$

Therefore, $\left\{\left\|x_{n}-p\right\|\right\}$ is a decreasing sequence and hence $\left\{\left\|x_{n}-p\right\|\right\}$ is convergent. So $\left\{x_{n}\right\}$ is bounded. From the uniform convexity of a Banach space $X$ and by Proposition 15 , there exists a strictly increasing, continuous and convex function $\varphi:[0,1) \rightarrow[0,1)$ such that $\varphi(0)=0$ and

$$
\begin{aligned}
\| x_{n+1}- & p \|^{2} \\
= & \left\|\alpha\left(x_{n}-p\right)+(1-\alpha)\left(T^{2} x_{n}-p\right)\right\|^{2} \\
\leq & \alpha\left\|x_{n}-p\right\|^{2}+(1-\alpha)\left\|T^{2} x_{n}-T^{2} p\right\|^{2} \\
& -\alpha(1-\alpha) \varphi\left(\left\|x_{n}-T^{2} x_{n}\right\|\right) \\
\leq & \left\|x_{n}-p\right\|^{2}-\alpha(1-\alpha) \varphi\left(\left\|x_{n}-T^{2} x_{n}\right\|\right) .
\end{aligned}
$$

Thus

$$
\alpha(1-\alpha) \varphi\left(\left\|x_{n}-T^{2} x_{n}\right\|\right) \leq\left\|x_{n}-p\right\|^{2}-\left\|x_{n+1}-p\right\|^{2},
$$

which implies that $\varphi\left(\left\|x_{n}-T^{2} x_{n}\right\|\right) \rightarrow 0$. Since $\varphi$ is strictly increasing and continuous at 0 , it follows that $\left\|x_{n}-T^{2} x_{n}\right\| \rightarrow$ 0 .

$$
\left\|x_{n}-T^{2} x_{n}\right\| \longrightarrow 0
$$

On the other hand, since $T^{2}$ is hemicompactness on $A$, there exists a subsequence $\left\{x_{n_{j}}\right\}$ of the sequence $\left\{x_{n}\right\}$ such that $x_{n_{j}} \rightarrow q \in A$. By the continuity of the mapping $T^{2}$ on $A$, we have $T^{2} x_{n_{j}} \rightarrow T^{2} q$. Since $\left\|x_{n_{j}}-T^{2} x_{n_{j}}\right\| \rightarrow 0$, we obtain $q=$ $T^{2} q$. Hence $q \in A$ is a fixed point of the mapping $T^{2}$ in $A$ and again by Lemma 6, $q$ is a best proximity point of $T$ in $A$ and $x_{n} \rightarrow q \in A$ strongly.

\section{Acknowledgement}

The research of N. Shahzad was partially supported by Deanship of Scientific Research (DSR), King Abdulaziz University, Jeddah, Saudi Arabia.

\section{References}

[1] W. A. Kirk, P. S. Srinivasan, and P. Veeramani, "Fixed points for mappings satisfying cyclical contractive conditions," Fixed Point Theory, vol. 4, no. 1, pp. 79-89, 2003.

[2] A. A. Eldred and P. Veeramani, "Existence and convergence of best proximity points," Journal of Mathematical Analysis and Applications, vol. 323, no. 2, pp. 1001-1006, 2006.

[3] T. Suzuki, M. Kikkawa, and C. Vetro, "The existence of best proximity points in metric spaces with the property UC," Nonlinear Analysis. Theory, Methods and Applications, vol. 71, no. 7-8, pp. 2918-2926, 2009.

[4] A. A. Eldred, W. A. Kirk, and P. Veeramani, "Proximal normal structure and relatively nonexpansive mappings," Studia Mathematica, vol. 171, no. 3, pp. 283-293, 2005.

[5] S. S. Basha and N. Shahzad, "Best proximity point theorems for generalized proximal contractions," Fixed Point Theory and Applications, vol. 2012, p. 42, 2012. 
[6] W. S. Du and H. Lakzian, "Nonlinear conditions for the existence of best proximity points," Journal of Inequalities and Applications, vol. 2012, p. 206, 2012.

[7] M. Derafshpour, S. Rezapour, and N. Shahzad, "Best proximity points of cyclic $\phi$-contractions in ordered metric spaces," Topological Methods in Nonlinear Analysis, vol. 37, no. 1, pp. 193202, 2011.

[8] M. Gabeleh, "Proximal weakly contractive and proximal nonexpansive non-self-mappings in metric and Banach spaces," Journal of Optimization Theory and Applications, vol. 2012, 2012.

[9] M. Gabeleh, "Best proximity points: global minimization of multivalued non-self mappings," Optimization Letters, vol. 2013, 2013.

[10] H. K. Pathak and N. Shahzad, "Convergence and existence results for best C-proximity points," Georgian Mathematical Journal, vol. 19, no. 2, pp. 301-316, 2012.

[11] G. S. R. Kosuru and P. Veeramani, "A note on existence and convergence of best proximity points for pointwise cyclic contractions," Numerical Functional Analysis and Optimization, vol. 32, no. 7, pp. 821-830, 2011.

[12] S. Ishikawa, "Fixed points by a new iteration method," Proceedings of the American Mathematical Society, vol. 44, pp. 147-150, 1974.

[13] H. K. Xu, "Inequalities in banach spaces with applications," Nonlinear Analysis. Theory, Methods and Applications, vol. 16, no. 12, pp. 1127-1138, 1991. 


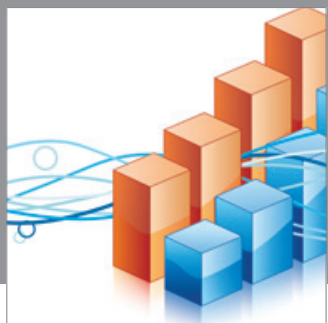

Advances in

Operations Research

mansans

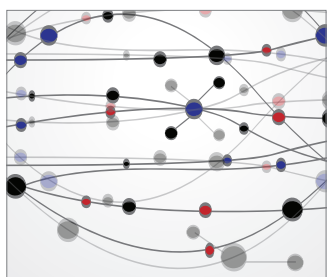

The Scientific World Journal
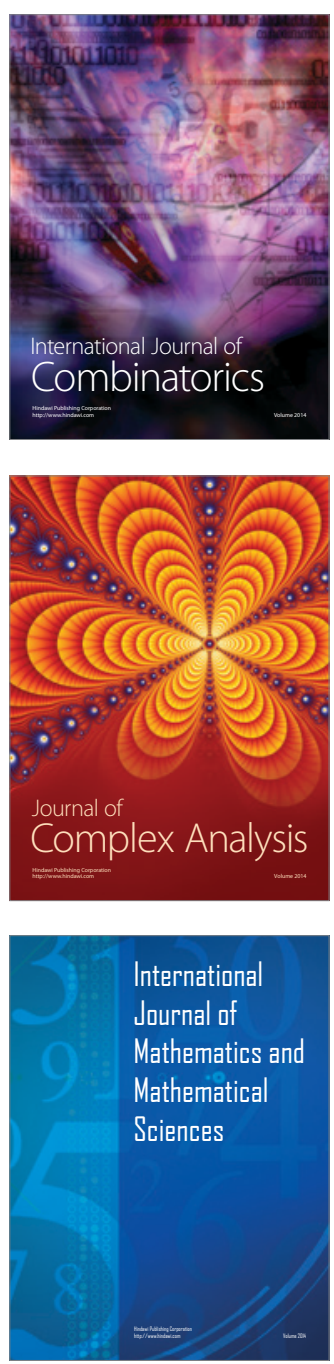
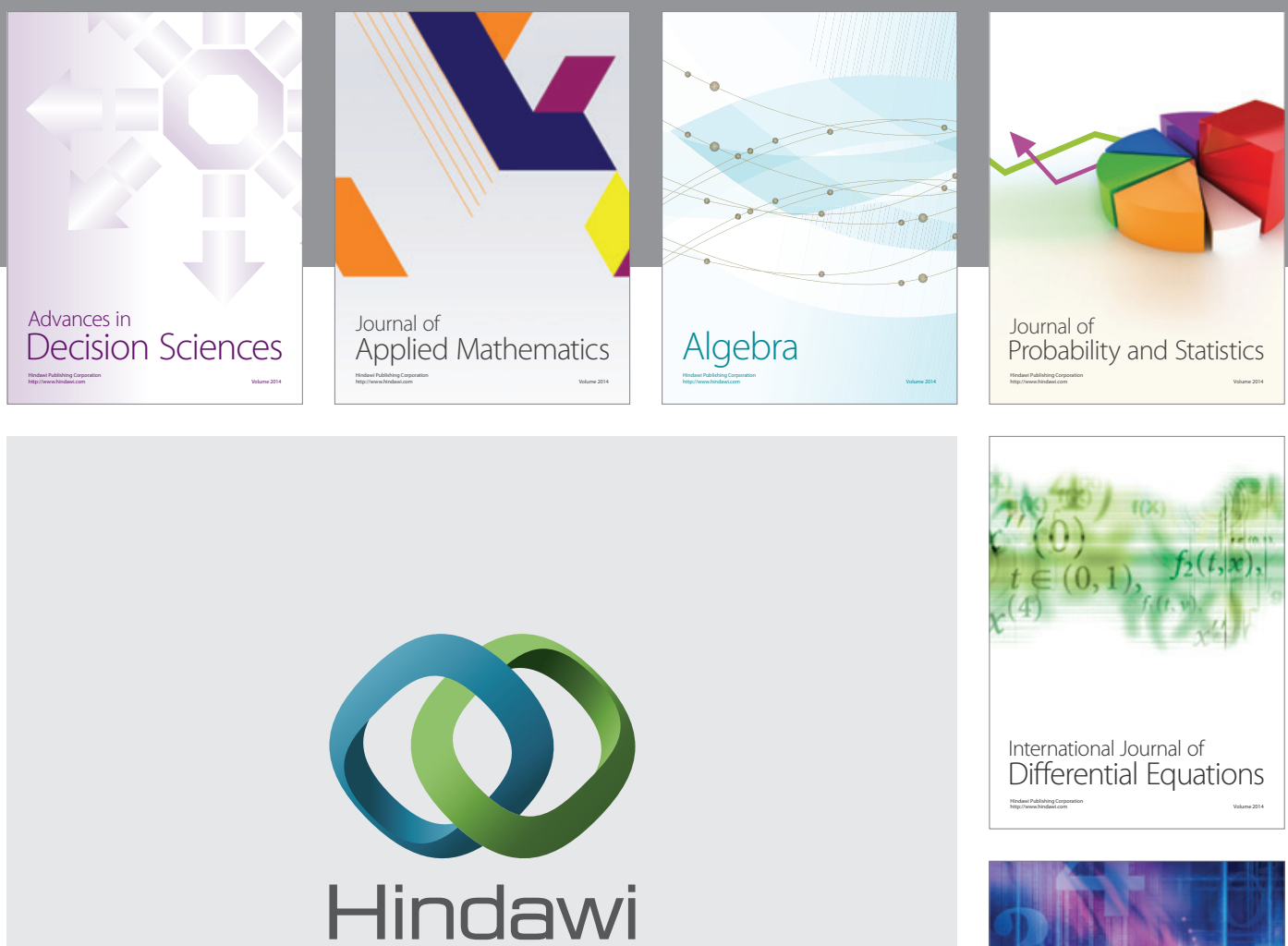

Submit your manuscripts at http://www.hindawi.com
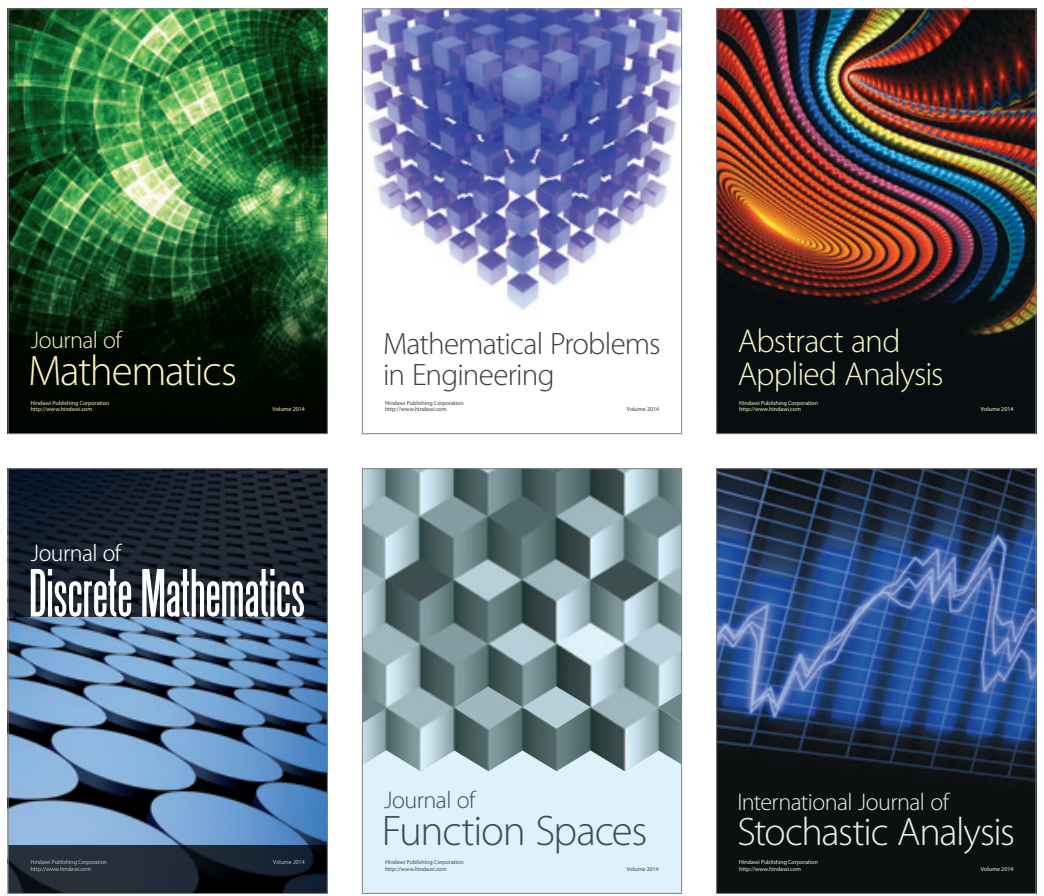

Journal of

Function Spaces

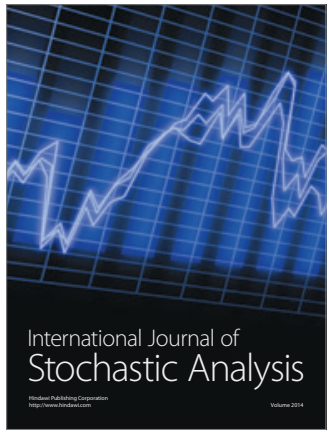

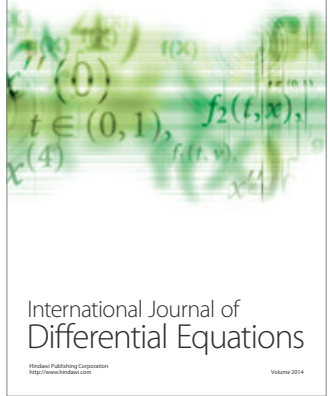
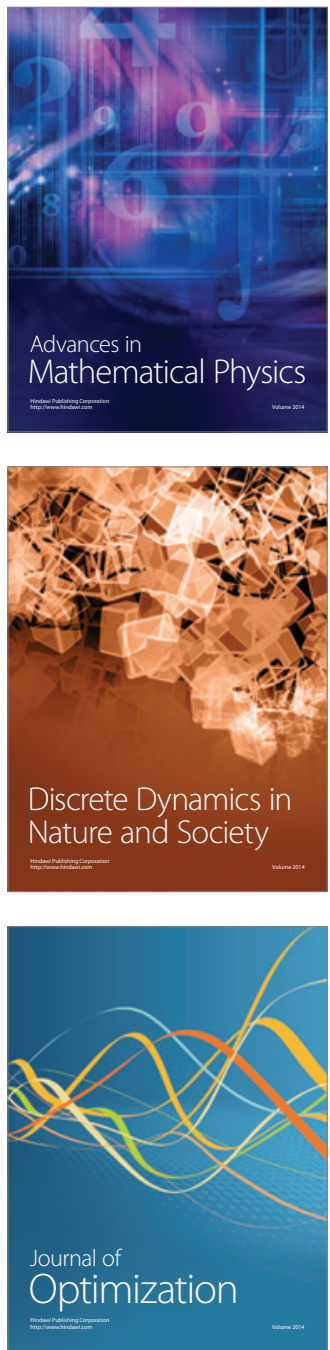